\title{
Scientific Communication between Spanish and English Educational Technology Journals. A Citation Analysis of eight Journals
}

\author{
Victoria I. Marín® and Olaf Zawacki-Richter॰ \\ Department of Educational Sciences, Center for Open Education Research (COER), University of Oldenburg, Germany
}

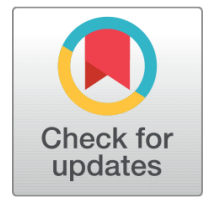

Received 08/01/2019

Revised 11-01-2019

Accepted 07/02/2019

Published 15/07/2019

\section{Corresponding Author}

Victoria I. Marín,

victoria.marin@uni-oldenburg.de

Carl von Ossietzky Universität Oldenburg, Department of Educational Sciences Ammerländer Heerstraße 138 26129 Oldenburg, Germany

DOI https://doi.org/10.7821/ naer.2019.7.393

Pages: 96-111

Distributed under

Creative Commons CC BY 4.0

\section{ABSTRACT}

In order to disseminate the findings and recommendations from their studies, researchers publish papers in scientific journals in their subject area. Research communities thus emerge as a result of the communication between authors who cite other relevant papers. This study focuses on the relationships between Spanish and English research communities in the specific field of Educational Technology. We explore as hypotheses whether there are signs of scientific journal communication between authors in these two communities, and if the English authors reciprocate citations by Spanish authors. In order to verify them, a social network analysis was conducted by considering outgoing and incoming citations in eight open access journals (four in English and four in Spanish) published over ten years (2007-2016). The sample includes 3,407 articles, which were analysed using UCINET and Gephi software. The results show partial confirmation of the hypotheses, since two separate research communities were recognized, with almost no communication between them. However, the Spanish community was presented as more connected than the English one. We interpret these results by considering not only language factors, but also the journal roots and the particular subject field under consideration. Finally, we highlight some general recommendations to enhance future communication between these two education research communities.

\section{Keywords SCIENTIFIC JOURNALS, EDUCATIONAL TECHNOLOGY, SCIENTIFIC COMMUNITIES, QUANTITATIVE ANALYSIS, CITATION ANALYSIS}

\section{INTRODUCTION}

Reading journal articles and publishing their own research results are a fundamental aspect of the life of academics in order to make meaningful contributions to their particular field of study. By consulting the list of references in particular research papers, researchers also have a valid way of finding out about other articles related to their topic, and which other journals serve the same area. Moreover, citing an article is an acknowledgment of the work of other researchers and constitutes an objective way of evaluating other studies (Franco,

\section{OPEN ACCESS}


Sanz, \& Culebras, 2016). Such activities contribute towards building a research community network and demonstrate the exchange of scientific information in the "intellectual structure of a given discipline" (Liu and Wang, 2005, p.308). Community networks can be explored by analysing the citation patterns among different journals, and by using social networking analysis. Liu and Wang (2005, p. 308) suggest that citation analysis has been frequently used to explore the knowledge structure of a given discipline and that "internal and external scholarly communication of a discipline can be understood by mapping its published literature". However, looking at citations presents certain limitations, which are important to acknowledge. For example, citations may be produced for other purposes besides conveying background literature, such as self-citing (own publicity) or criticizing another's work. There are also reasons for a lack of citation, such as not being aware of prior research, previous literature not considered to be relevant, or difficulties in accessing the work (e.g. a fee may be required, or the article may be in another language). Nevertheless, citation data provides an objective measure to describe the flow of communication in a research discipline (and by implication the creation of scientific communities), as well as the relationships between journals (Zawacki-Richter \& Anderson, 2011).

Various considerations need still to be taken into account. Different studies in the bibliometric field, which are mentioned as follows, show that the language in which academic papers are written is clearly decisive when papers are selected for citation. For instance, Leon-Sarmiento, Leon-S, and Contreras (2007)found that papers published in English language journals seldom cite articles published in other languages. Furthermore, articles written in English have a better chance of being cited in journals in the same language, since databases contain a considerably higher percentage of English articles (in all fields) compared to any other language, including Spanish - and this situation is more acute in social sciences and humanities (Buela-Casal, 2003; Franco et al., 2016; López-Navarro, Moreno, Quintanilla, \& Rey-Rocha, 2015; Ruiz-Corbella, Galán, \& Diestro, 2014). This situation constitutes a significant language bias in journal impact factors. Current initiatives such as the Information Matrix for the Analysis of Journals (MIAR ${ }^{1}$ ) (Urbano et al., 2005), the Integrated Classification of Scientific Journals (CIRC) with the focus on social sciences and humanities journals (Torres-Salinas et al., 2010; Torres-Salinas \& Repiso, 2016), the national award of the FECYT seal for Spanish quality journals ${ }^{2}$ (originated in 2016) and Altmetrics (Torres-Salinas, Cabezas-Clavijo, \& Jiménez-Contreras, 2013) can elevate the visibility of Spanish journals. Another study presents Google Scholar as a very useful tool for examining the social sciences works in non-Anglophone countries compared to traditional bibliographic databases (Gantman \& Dabós, 2018). These tools allow researchers to compare Spanish publications in a specific field with a selection of relevant papers internationally and to access available - but usually dispersed - information on the quality of the respective journals. In addition, Altmetrics enables researchers to track and consider the online impact of their publications in different virtual spaces, as an alternative indicator of impact that is gaining relevance in the new context of open science and open

\footnotetext{
${ }^{1}$ http://miar.ub.edu/

${ }^{2}$ https://evaluacionarce.fecyt.es/
} 
access for Education journals (Diestro, Ruiz-Corbella, \& Galán, 2017). However, there is also skepticism regarding the usefulness of those alternative bibliometric indicators and methods without additional measures for scientific evaluation, especially in Spain and Latin America (Robinson-García, Repiso, \& Torres-Salinas, 2018).

In order to find out if these statements are also true for the Educational Technology (ET) field - in which many recognized journals are published in Spanish - we analysed the ET research communities in English and Spanish. This article maps out the structure of ET journal networks using cross-citation data to investigate the communication patterns between the Spanish and English-speaking worlds, based on eight selected journals in the field. Although we are aware that citation analysis is not one of most often methods within Education, the contribution of this paper focuses on the specific community of ET within the Education area and offers an alternative methodological perspective to look at the educational phenomenon in future work.

Our hypotheses are the following:

- The Spanish and English ET research communities are two distinct communities with little communication between them.

- Spanish ET authors cite English papers, but English ET authors do not reciprocate citations.

Therefore, the objectives of the study are:

1. Analyse the communication patterns between Spanish and English ET research communities.

2. Identify differences in the communication patterns among Spanish and English ET research communities.

The following research questions related to the objectives were then explored:

- Are Spanish and English research communities in the field of ET isolated from each other?

- How often do Spanish authors cite English papers in the field of ET, and vice versa?

- What are the communication patterns between Spanish and English ET journal networks?

The answers to these questions are presented in this paper, together with implications and conclusions.

\section{MATERIAL AND METHODS}

\subsection{Social Network Analysis}

In this study, social network analysis (SNA) was applied to unveil communication patterns between the two research communities through their publications in academic journals in 
the field of ET. SNA is an interdisciplinary approach that combines network and graph theory to represent the relationships between actors in the form of a social network diagram ha (Haythornthwaite, 1996; Wasserman \& Faust, 1994). It is one of the most current and frequently used research methods to produce visual representations of scholarly communication networks in the social and behavioural sciences (e.g. in the field of distance education, see Zawacki-Richter and Anderson, 2011). For instance, SNA has also been used within the Education area to analyse the differences in the development of personal networks of high and low-performing students based on their final academic grades and their participation in two online courses (Casquero, Ovelar, Romo, \& Benito, 2015), to conceptualise and explore virtual communities (Chiu, Hsu, \& Wang, 2006; Dholakia, Bagozzi, \& Pearo, 2004) or to analyse patterns of international student mobility (Kondakci, Bedenlier, \& Zawacki-Richter, 2018).

Within the broader method of SNA, citation analysis enables the study of the structure of different disciplines, based on the relationships among authors, articles and journals as measured by citations of sources within published papers (Otte \& Rousseau, 2002; Rice, Borgman, Bednarski, \& Hart, 1989). Another tool is network theory (Borgatti, Mehra, Brass, \& Labianca, 2009), which has been used to examine the relationships between journals and their similarities in citations, in order to generate citation matrices and maps of journals (Xhignesse \& Osgood, 1967). The same authors found that perhaps the best single index of a journal's scholarliness is the density of citation, that is, how much its authors depend upon their knowledge of the work of others (Xhignesse \& Osgood, 1967).

Vargas et al. (2010) define social networks as the relationships between research individuals and organizations that work and exchange information among themselves, through nodes of high productivity. While connecting with others, researchers share their expertise and knowledge (social capital). Within such networks, individuals and organizations tend to be familiar with only that part of the overall social network to which they belong. Therefore, in order to increase the sharing of social capital, it is important for each member in the network to reach out and communicate with others beyond those to whom they are directly connected. Every member of the network is called a 'node' (actor), and the connections or relationships among them are called 'edges' (ties) (Wasserman \& Faust, 1994).

We summarize the research method used in this study for the analysis of communication patterns across various selected journals as 'journal network analysis', based on SNA. The collection of ET journals can be described as a network, in which nodes are the journals and the ties or edges are the citations between them. Using SNA, different aspects of the network can be investigated, such as the relationships, prestige and centrality of the actors (the journals).

For example, the degree of a node, $\mathrm{d}\left(\mathrm{n}_{i}\right)$, in a network is the number of ties that are incident with it or the number of nodes adjacent to it (Wasserman \& Faust, 1994). A prominent, central journal in the network is one that is extensively involved in relationships with other journals in terms of citations. The outgoing-incoming ratio is defined as the number of citations a journal sends to another journal divided by the frequency with which the journal receives citations from other journals in the network. High values suggest that the journal 
is a 'feeder' of citations, while lower values suggest that the journal is a 'storer' of citations. The self-feeding ratio is defined as the relative frequency with which a journal cites itself. The prestige or status of a journal in the network increases as it becomes the object of more ties (known as the indegree), but not necessarily when ties are initiated by the journal itself (outdegree). Therefore, another important concept is network congruence, which is defined by the extent to which journals in the network cite other journals in proportion to the number of times they are themselves cited by those journals (see Eagel, 1975, for congruence in journal networks). Thus, in a network with a high congruence, $\mathrm{X}_{i k}$ is highly correlated with $\mathrm{X}_{k i}$.

In addition, the absolute level of citation depends on the size of the journal (larger journals with more issues and papers per volume probably receive more citations than smaller journals(Table 1); however, the citation pattern is not a function of size. Thus, the structure of the journal network must be viewed without any confounding effects due to size by standardizing the outgoing and incoming citations, which is done by dividing them by the number of papers published between the considered periods of time in each journal. The mean standardized tie density can be used as a cut-off point to produce dichotomized citation matrices in which tie densities above that point are coded as 1, and below it as 0 (Doreian \& Fararo, 1985).

There are many software applications, both free and commercial, that can be used for SNA and hence for journal network analysis. Such applications usually offer the following sort of functionality that is characteristic of this method of analysis: 1. researchers can represent data in a systematic way; 2 . different means of data visualization are possible; 3. researchers can characterize the data by indicators (density, distance, centrality...); and 4. insights are enabled to detect community formation. The most well-known free SNA tools are Pajek (used by Vargas et al., 2010) and Gephi (open source) (used by Bastian, Heymann, and Jacomy, 2009). Commercial SNA tools include UCINET and NetDraw (Zawacki-Richter \& Anderson, 2011). In the current work both UCINET 6 (Borgatti, Everett, \& Freeman, 2002) and Gephi 0.9.1 software (Bastian et al., 2009) were employed. Gephi uses the Louvain method (Blondel, Guillaume, Lambiotte, \& Lefebvre, 2008) to highlight communities that are evident in networks. The community detection algorithm creates a modularity class value for each journal, which is helpful for the posed objectives.

\subsection{Sample}

Eight Educational Technology journals were selected as a sample for the journal network analysis in this study (see Table 1). Since the number of Spanish ET journals was smaller than the English one, the sample of Spanish journals were selected in the first place, based on their thematic content (mostly publishing ET general -related articles and not focusing on specific subtopics, such as, e.g., distance education or e-learning), being well-established journals of the field for longer time and a Spanish origin ${ }^{3}$. The selection of the English ET journals was done next and, in order to choose the most comparable publications possible,

\footnotetext{
${ }^{3}$ List of Educational Spanish scientific journals (with at least 100 papers in the last 5 years): https://www.re vistacomunicar.com/metaranking/metaranking.php?area=educacion
} 
we followed these criteria, in addition to the thematic ones:

- Open Access journals, with no need to pay a subscription fee to access articles and without article processing charges, as was the case of the selected Spanish journals. Different authors have shown that open access articles have a greater research impact in terms of citations per article and are also cited earlier than papers in non-open access journals, among other factors, due to their free availability on the Internet, among other factors (Antelman, 2004; Gargouri et al., 2010; Harnad \& Brody, 2004; Zawacki-Richter, Anderson, \& Tuncay, 2010)

- Similar impact in terms of cites per paper of each of the Spanish journals calculated using the 'Publish or Perish' software that Google Scholar employed as a source (Harzing, 2007) during the time period 2014-2016 (as of summer 2017), since not all the journals were on Scopus or Social Sciences Citation Index (SSCI), particularly the Spanish ones.

All full papers $(\mathrm{N}=3,407)$ published in the selected journals between 2007 and 2016 were included in the sample. Study book reviews, editorials, erratum, etc. were excluded from the sample. The year chosen as the start date (2007), corresponds (for some of the publications) to the beginning of them being indexed in Scopus. This database was chosen over SSCI and others based on the inclusion of most of the issues of the journals selected.

Table 1 Selected journals for the study. ( $\mathrm{n}$ is the number of articles published between 2007 and 2016)

Journal

International Journal of Computer-Supported Collaborative

IEEE Transactions on Learning Technologies (IEEE TLT)

Australasian Journal of Educational Technology (AJET)

Educational Technology and Society (ETS)

Comunicar

RUSC. Universities and Knowledge Society Journal/Revista de Universidad y Sociedad del Conocimiento ${ }^{* * *}$

Edutec-e. Revista Electrónica de Tecnología Educativa

Píxel-bit. Revista de Medios y Educación

Total $(\mathrm{N})$
Learning (IJCSCL)

Start year of

publication

\begin{tabular}{cccc}
2006 & English & 196 & 5.75 \\
$2008^{*}$ & English & 265 & 7.78 \\
1985 & English & 565 & 16.58 \\
1998 & English & 986 & 28.94 \\
1993 & Spanish and English & 555 & 16.29 \\
2004 & Spanish and English & 257 & 7.54 \\
& & & \\
1995 & Spanish & 274 & 8.04 \\
1994 & Spanish & 309 & 9.07 \\
& & 3,407 & 100 \\
\hline
\end{tabular}

Note: ${ }^{\star}$ IEEE TLT started publication from 2008 , so it does not have any papers published in $2007 .{ }^{\star \star}$ Some of the Spanish journals started publishing articles only in Spanish, but they now publish articles both in English and Spanish (e.g. Comunicar) or only in English (e.g. RUSC, since 2016). ${ }^{\star * *}$ Since 2016: RUSC changed to become International Journal of Educational Technology in Higher Education (IJETHE). The journal was bilingual from 2010 to 2015.
We acknowledge that the sample of selected Spanish and English ET journals was reduced to match each by each the impact described; therefore, others could still meet the criteria to be in the sample (e.g. Digital Education Review -DER- or Revista Iberoamericana de Educación a Distancia -RIED- from the Spanish side, or the International Review of Research in Open and Distributed Learning IRRODL- as English ET journal). 
The four Spanish journals in the sample emerged originally in Spain: Comunicar in Huelva, Píxel-Bit in Sevilla, Edutec in Palma de Mallorca and RUSC/IJETHE in Barcelona. Only two of them remain as university-managed publications: Píxel-Bit by the University of Sevilla, and Edutec by the University of the Balearic Islands (although this journal is edited by the Ibero-American Edutec Association). Comunicar is managed by the private and non-profit association with the same name; IJETHE started originally to be edited by the Open University of Catalonia and currently published by Springer. Regarding the subject field, all the Spanish journals have 'Education' as an exclusive subject field, with the exception of Comunicar, which lists 'Mass Communication' as its major subject area (according to MIAR). The four of them are considered the most well-recognised and oldest Spanish journals in the field of Educational Technology.

The four English journals have various origins. IJCSCL is supported by the International Society of Learning Sciences and is edited by Springer. Its focus is on ComputerSupported Collaborative Learning, combining technical issues and educational aspects, and it was founded in cooperation between Germany and the United States. AJET has its origins in Australia and it is published by the Australasian Society for Educational Technology, with a focus on studies in post-school educational settings. ETS and IEEE were both founded in the USA and are published respectively by the IEEE Computer Society and the Institute of Electrical and Electronics Engineers. For all of these journals (with the exception of AJET), the first subject area specified in the Scientific Journal Rankings (SJR) ranking is either 'Engineering' and/or 'Computer Science', and in second place is 'Social Sciences' with 'Education' as a subcategory. AJET has as an exclusive subject area and category 'Social Sciences'> 'Education'; in other words, there is no 'Engineering' or 'Computer Sciences' in the first field.

All journal issues were indexed in Scopus, with the exception of Edutec-e and Pixelbit, and those in AJET in 2007, Comunicar in 2007 and RUSC between 2007 and 2011. In addition, during the analysis, some articles in specific issues were detected as not being indexed in Scopus. In those cases, the citations between the journals were counted manually based on the information available in the journals' websites.

The data collection strategy via Scopus included searching for the source title (title of the journal), filtering by year and type of publication (articles only) and selecting the option to obtain the references used in those articles. Then the source title was filtered again to check the sample of journals. The dataset was collected and counted by creating tables in a Microsoft Excel file.

\section{RESULTS}

\subsection{Citation network matrix}

The network of outgoing and incoming citation ties is presented in as an 8x8 matrix whose $\mathrm{X}_{i j}$ elements give the frequency with which the $\mathrm{j}^{\text {th }}$ journal cites articles published in the $\mathrm{i}^{\mathrm{t}}$ journal. Between 2007 and 2016 a total of 3,407 articles were published in the eight journals. These articles contained a total of 3,431 citations within the network. 
Table 2 Citation network (2007-2016)

\begin{tabular}{|c|c|c|c|c|c|c|c|c|c|c|c|}
\hline \multicolumn{12}{|c|}{ Cited Jounal } \\
\hline & & $\mathrm{J1}$ & $\mathbf{J} 2$ & $\mathbf{J 3}$ & $\mathbf{J 4}$ & J5 & J6 & J7 & J8 & Total b & Total $\mathbf{b}^{\star}$ \\
\hline IJCSCL & $\mathrm{J1}$ & 173 & 8 & 3 & 18 & 0 & 0 & 0 & 0 & 202 & 29 \\
\hline IEEE TLT & $\mathrm{J} 2$ & 49 & 104 & 11 & 57 & 0 & 0 & 0 & 0 & 221 & 117 \\
\hline AJET & J3 & 33 & 8 & 390 & 87 & 0 & 1 & 0 & 0 & 520 & 130 \\
\hline ETS & $\mathrm{J4}$ & 74 & 41 & 103 & 596 & 2 & 0 & 1 & 0 & 818 & 222 \\
\hline Comunicar & J5 & 6 & 1 & 5 & 12 & 232 & 14 & 8 & 28 & 309 & 77 \\
\hline RUSC/IJETHE & J6 & 2 & 4 & 15 & 14 & 17 & 100 & 12 & 30 & 194 & 94 \\
\hline EDUTEC & J7 & 12 & 2 & 15 & 17 & 70 & 62 & 234 & 127 & 545 & 311 \\
\hline Pìxel-Bit & J8 & 1 & 1 & 11 & 19 & 92 & 48 & 74 & 387 & 641 & 254 \\
\hline Total a & & 350 & 169 & 553 & 820 & 413 & 225 & 329 & 572 & 3431 & \\
\hline Total $\mathbf{a}^{\star}$ & & 177 & 65 & 163 & 224 & 181 & 125 & 95 & 185 & & 1215 \\
\hline $\begin{array}{l}\text { Self-feeding } \\
\text { ratio }\end{array}$ & & 0.49 & 0.62 & 0.71 & 0.73 & 0.56 & 0.44 & 0.71 & 0.68 & & \\
\hline
\end{tabular}

Note: $\mathrm{a}=$ incoming citations; $\mathrm{b}=$ outgoing citations; ${ }^{*}=$ self citations excluded

The entries in Table 2 can be viewed in terms of overall levels of citation (and corresponding densities) and patterns of citation. The citation data consists of valued directional relations in which the strength or intensity of each tie is recorded as the number of outgoing and incoming citations.

\subsection{Network density}

The density of this valued network is the total of all values (3,431 citations) divided by the number of possible ties ( 64 entries in the $8 \times 8$ matrix). This yields a mean citation rate across all journals of 53.6, which we refer to as the overall citation 'tie density'.

It should be noted that this type of network analysis (i.e. outgoing and incoming citations) is biased towards journals that have been published for a longer period of time (such as AJET or EDUTEC). A journal that did not publish prior to 2007 (IJCSCL and IEEE TLT) obviously cannot be cited for publications before that date, whereas older journals potentially gain citations from the date of first publication. To control for the different journal sizes, the outgoing and incoming citations were standardized by dividing them by the number of papers published between 2007 and 2016 in each journal. This yields a value of 3.5 total citations per paper (excluding self-citations) and an overall standardized tie density of 0.06 citations per paper in the $8 \times 8$ matrix.

It is remarkable that the number of self-citations, i.e. citations to other papers published in the same journal, is relatively high in this network of English and Spanish educational technology journals. The self-feeding ratio is defined as the relative frequency with which a journal cites itself. The average self-feeding ratio is 0.62 in the total network, ranging from 0.44 (RUSC) to 0.73 (ETS).

In addition, the density for the Spanish and English journal networks were looked at separately in the standardized citation network values. Whereas the English network has a density of 0.086 (excluding self-citations), the mean citation rate between the Spanish 
journals is almost as twice as high (0.163).

Table 3 Standardized citation network (2007-2016)

Cited Journal

\begin{tabular}{lcccccccccc}
\hline & & J1 & J2 & J3 & J4 & J5 & J6 & J7 & J8 & Total b \\
IJCSCL & J1 & 0.883 & 0.041 & 0.015 & 0.092 & 0 & 0 & 0 & 0 & 1.031 \\
IEEE TLT & J2 & 0.185 & 0.392 & 0.042 & 0.215 & 0 & 0 & 0 & 0 & 0.834 \\
AJET & J3 & 0.058 & 0.014 & 0.690 & 0.154 & 0 & 0.002 & 0 & 0 & 0.919 \\
ETS & J4 & 0.075 & 0.042 & 0.104 & 0.604 & 0.002 & 0 & 0.001 & 0 & 0.829 \\
Comunicar & J5 & 0.011 & 0.002 & 0.009 & 0.022 & 0.418 & 0.025 & 0.014 & 0.050 & 0.551 \\
RUSC/IJETHE & J6 & 0.008 & 0.016 & 0.058 & 0.054 & 0.066 & 0.389 & 0.047 & 0.117 & 0.755 \\
EDUTEC & J7 & 0.044 & 0.007 & 0.055 & 0.062 & 0.255 & 0.227 & 0.854 & 0.464 & 1.967 \\
Pixel-Bit & J8 & 0.003 & 0.003 & 0.036 & 0.061 & 0.298 & 0.155 & 0.239 & 1.252 & 2.049 \\
Total a & & 1.267 & 0.517 & 1.009 & 1.265 & 1.039 & 0.798 & 1.156 & 1.883 & 17.867 \\
\hline
\end{tabular}

Note: $\mathrm{a}=$ incoming citations; $\mathrm{b}=$ outgoing citations

The standardized tie density (i.e. 0.06 citations per paper for the overall network) was used as the cut-off point, to draw an image matrix of the network (Table 4). The rows show the citing and the columns the cited journals.

\begin{tabular}{|c|c|c|c|c|c|c|c|c|c|}
\hline & & $\mathrm{J1}$ & $\mathrm{J} 2$ & J3 & $\mathrm{J4}$ & J5 & J6 & J7 & J8 \\
\hline IJCSCL & $\mathrm{J1}$ & - & 0 & 0 & 1 & 0 & 0 & 0 & 0 \\
\hline IEEE TLT & $\mathbf{J 2}$ & 1 & - & 0 & 1 & 0 & 0 & 0 & 0 \\
\hline AJET & $\mathbf{J 3}$ & 0 & 0 & - & 1 & 0 & 0 & 0 & 0 \\
\hline ETS & $\mathrm{J4}$ & 1 & 0 & 1 & - & 0 & 0 & 0 & 0 \\
\hline Comunicar & J5 & 0 & 0 & 0 & 0 & - & 0 & 0 & 0 \\
\hline RUSC/IJETHE & J6 & 0 & 0 & 0 & 0 & 1 & - & 1 & 1 \\
\hline EDUTEC & J7 & 0 & 0 & 0 & 1 & 1 & 1 & - & 1 \\
\hline Pìxel-Bit & J8 & 0 & 0 & 0 & 1 & 1 & 1 & 1 & - \\
\hline
\end{tabular}

The network graph depicted in Figure 1 is based on the dichotomized matrix in Table 3, showing ties that are above the cut-off point ( 0.06 citations per paper). If the number of citations per paper is less than or equal to 0.06 , the tie is coded as absent; otherwise, the tie is coded as present.

\subsection{Network modularity}

The community detection algorithm of Gephi creates a modularity class value for each journal, which is used to color code communities within the Educational Technology research network (see Figure 1). The analysis shows the existence of two sub-networks: the English (red nodes) and Spanish (green nodes) groups of research journals.

Looking at relationships between English (red ties) and Spanish journals (green ties), the figure reveals that they exchange information mainly within their respective research 


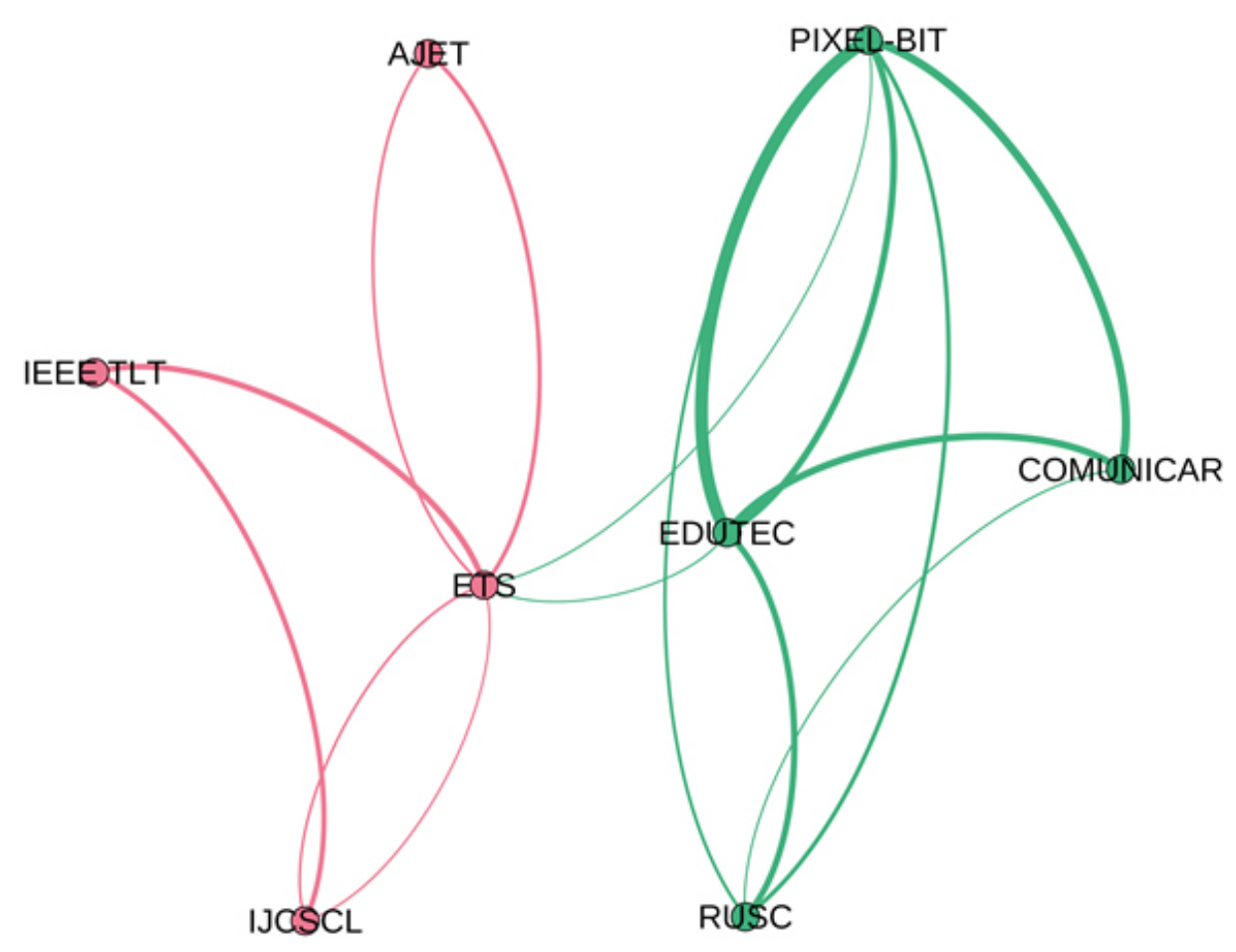

Figure 1 Network diagram of standardized citing and cited data with threshold $>=0.06$

communities, with 3.61 citations per paper within the English group of journals and 4.87 citations per paper within the Spanish group. Authors who publish in Spanish journals refer to papers that are published in English journals ( 0.45 citations per paper), but their citations are not reciprocated (there are only 0.005 citations per paper from English to Spanish journals). Above the threshold of 0.06 citations per paper, only Píxel-Bit and EDUTEC refer to ETS but not vice versa.

\subsection{Centrality and prestige}

Based on the standardized citation data (excluding self citations), the most central journal in terms of the highest total number of incoming citations per paper (indegree) is ETS (0.66), followed by three Spanish journals: Píxel-Bit (2.06), Comunicar (0.62), and RUSC (0.41) (Table 5 ).

\subsection{Outgoing-incoming ratio and network congruence}

The top 'storers' of citations are journals that receive many more citations from other journals than they send out (above 1.0): IJCSCL (0.58) and Comunicar (0.75), while EDUTEC (1.66) and IEEE TLT (1.31) are the strongest 'feeders'. Journals that show a congruent citation pattern with an outgoing-incoming ratio around 1 are ETS (0.97), Píxel-Bit (1.07), and AJET (0.91). The correlation between outgoing and incoming citations (Network congruence) reveals that the total journal network in this study is quite symmetric $(\mathrm{r}=0.88)$. 


\begin{tabular}{llll}
\hline \multicolumn{2}{l}{ Table 5} & Ranking of journals based on standardized indegree (citations per paper), excluding self-citations \\
Rank & Journal & StdIndegree & Indegree $^{*}$ \\
\hline 1 & J4 ETS & 0.66 & 224 \\
2 & J8 Píxel-Bit & 0.6 & 185 \\
3 & J5 Comunicar & 0.62 & 181 \\
4 & J6 RUSC/IJETHE & 0.41 & 125 \\
5 & J1 IJCSCL & 0.38 & 177 \\
6 & J3 AJET & 0.32 & 163 \\
7 & J7 EDUTEC & 0.30 & 95 \\
8 & J2 IEEE TLT & 0.12 & 65 \\
\hline
\end{tabular}

Note: ${ }^{\star}$ Total number of incoming citations, self-citations excluded

\section{DISCUSSION AND CONCLUSIONS}

The SNA of the two groups of journals in our sample confirms both our hypotheses. Concerning the first hypothesis, two ET research communities can be clearly distinguished by the language of publication, but the communication between them is rather sporadic. Only two of the Spanish journals (Píxel-Bit and Edutec) cite the English journal ETS to a notable extent, but no substantial ties were identified from the English journals to the Spanish ones. That fact confirms our second hypothesis: Spanish ET authors cite papers in English journals, but they are not reciprocated. In addition, it should be mentioned that, although the network congruence was found to be quite symmetric, Zawacki-Richter and Anderson (2011) found a lower average self-feeding ratio (0.47) than in this ET network (0.62) in a similarly thematic English journal network (distance education), which may suggest that some journals in our network have a self-citing pattern higher than the others and should be considered as a limitation for the study.

Regarding the first research objective, we can then highlight an isolated communication pattern between Spanish and English ET research communities, which could be interpreted in different ways. In this study, we cannot attribute it to the need for a subscription fee, since we purposefully selected open access journals. The most plausible reason could be lack of knowledge of the language in which the other journal is published (more probable within the English community). Our findings confirm the ones of different authors, such as Franco et al. (2016), López-Navarro et al. (2015), and Leon-Sarmiento et al. (2007), namely that journals which publish in English seldom cite articles published in other languages (in this case, Spanish). However, even in the case of the hybrid journals, in which both English and Spanish articles can be found, there are no meaningful ties to give support to the argument that having English articles would result in more citations by authors that write in that language. The originally Spanish-based journals, regardless of containing English articles (RUSC/IJETHE) or publishing in both languages (Comunicar), are not taken into account by the authors that publish in English-speaking journals. In contrast to the study by Franco et al. (2016), we cannot prove from our sample that English articles have higher chances of being cited in English journals. It should also be noted that some of the Spanish journals were indexed in different recognized databases and most of them offer an abstract of 
the papers in both Spanish and English, which may be helpful to increase their visibility, but that was not the case in our study regarding the communication between English and Spanish journals. Thus, other reasons might be credible for both research communities: for example, not being aware of prior research, or considering previous literature as not relevant. We also point towards the differences among the subject topics in both research communities; and in other words, to the scope of the various journals, which was mentioned in the description of their subject fields.

Concerning the second research objective, differences in the communication patterns among Spanish and English ET research communities were identified: the Spanish ET research community seems to be closer and more tightly connected than the English one as the tie densities for each network show in our study. We can sustain that there is a higher level of communication between papers in the Spanish journals in terms of citations, since the mean citation rate is almost as twice higher than in the English network. That is especially the case for Comunicar, Píxel-Bit and Edutec, which could be partially explained by their relatively close launch years (1993, 1994 and 1995 respectively) at that time, no Spanish journals existed in this field (there were only general education or pedagogy journals). Other plausible reasons might be that the Spanish ET research community (and thus, the editorial teams of the journals) is smaller than the English one, meets regularly at similar national and Ibero-American conferences, and it is often active in sharing their work in academic and non-academic social networks. Therefore, even though language may be an important factor (Buela-Casal, 2003; Franco et al., 2016; Leon-Sarmiento et al., 2007; López-Navarro et al., 2015; Ruiz-Corbella et al., 2014), a further possible relevant element regarding the communication between the research communities may be the origin and editorial structure of the journals.

As limitations of the study, we acknowledge the small sample of selected Spanish and English ET journals and that a broader one may bring different results. However, previous research within bibliometrics, which is considered in this section, as well as in the introduction, seems to point towards this trend not only in Education, but also in a range of disciplines. Even though, our study brings a modest contribution to the provision of clear evidence regarding the need to find a way to bridge knowledge between those communities. Another limitation resides in the method used, which is limited inasmuch as it characterises the relationships between the Spanish and the English ET communities just in terms of journal citations. Other methods could shed light on different kinds of collaboration and/or provide nuanced interpretations of the results obtained in this study.

In line with the aims of different Spanish initiatives (CIRC, MIAR, FECYT seal), together with the implications of this study, we suggest that there is a need to improve the visibility of all the journals - especially the ones written in languages other than English and in social sciences and humanities - and to raise awareness of the research conducted in similar fields. Some guidelines for authors and readers of the Spanish and English ET communities include:

- Consulting comprehensive databases of peer-reviewed journals published in different countries (e.g., Latindex, SciELO, RedALyC) (Salager-Meyer, 2015) and using non- 
traditional bibliographic databases, such as Google Scholar (Gantman \& Dabós, 2018; Zhang, Lun, \& Yang, 2017)

- Incorporating in the own papers English-written titles, extended abstracts and keywords, along with translations of papers into English, when possible (Salager-Meyer, 2015).

- Considering alternative metrics such as taking advantage of Web 2.0 sharing and commenting possibilities and promoting open access measures, which should come along with decisions on the strategies for scientific digital dissemination of the universities (Diestro et al., 2017; Torres-Salinas, Castillo-Valdivieso, Pérez-Luque, \& Romero-Frías, 2018) and with changes in the evaluation processes of the scientific activity in Spain and Latin America (Rafel, 2016; Robinson-García et al., 2018).

As Ruiz-Corbella et al. (2014) point out, in social sciences and humanities there is no homogeneity internationally in the research interests and cultural differences, which include the cultural richness of languages, but also the differences in the contextualization of the topics, therefore should be closer considered than in other discipline areas. In addition, the same authors highlight that the Spanish research in our subject area is a referent for the Ibero American world and for the increasing Spanish-speaking population. Accordingly, research communities in Education could be developed further, with closer communication links including Spanish and English sides -in addition to other languages. In turn, such initiatives could enhance better knowledge transfer within the specific field of Educational Technology.

Future studies could also explore the authors' knowledge regarding foreign journals, but also the influence of the editorial journal guidelines concerning the internationalization promoted by the editorial journal teams, including the possibility of publishing papers in different language (e.g. in NAER, both in Spanish and English). Another line of research to be further developed is the one that focuses on exploring the arisen themes through content analysis of articles published in specific ET journals (Bond, Zawacki-Richter, \& Nichols, 2019; Marín, Duart, Galvis, \& Zawacki-Richter, 2018; Marín, Zawacki-Richter, Pérez, \& Salinas, 2017; Zawacki-Richter, Alturki, \& Aldraiweesh, 2017; Zawacki-Richter \& Latchem, 2018; Zawacki-Richter \& Naidu, 2016) or a specific field or topic through bibliometric research (Bartolomé, Castañeda, \& Adell, 2018; Tibaná-Herrera, Fernández-Bajón, \& Moya-Anegón, 2018), and especially emphasising the analysis of shared topics within the Spanish and English ET community to search for a nexus of work together.

\section{REFERENCES}

Antelman, K. (2004). Do open-access articles have a greater research impact? College \& Research Libraries, 65(5), 372-382. https://doi.org/10.5860/crl.65.5.372

Bartolomé, A., Castañeda, L., \& Adell, J. (2018). Personalisation in educational technology: the absence of underlying pedagogies. International Journal of Educational Technology in Higher Education, 15(14). https://doi.org/10.1186/s41239-018-0095-0

Bastian, M., Heymann, S., \& Jacomy, M. (2009). Gephi: An open source software for exploring and manipulating networks. Proceedings of the third international icwsm conference, menlo park, 
california (Vol. 15(1), pp. 361-362), The AAAI Press. Retrieved from http://doi.org/10.1136/ qshc.2004.010033

Blondel, V. D., Guillaume, J. L., Lambiotte, R., \& Lefebvre, E. (2008). Fast unfolding of communities in large networks. Journal of Statistical Mechanics: Theory and Experiment, 10, 1-12. https:// doi.org/10.1088/1742-5468/2008/10/P10008

Bond, M., Zawacki-Richter, O., \& Nichols, M. (2019). Revisiting five decades of educational technology research: A content and authorship analysis of the British Journal of Educational Technology. British Journal of Educational Technology. British Journal of Educational Technology, 50(1), 12-63. https://doi.org/10.1111/bjet.12730

Borgatti, S. P., Everett, M. G., \& Freeman, L. C. (2002). Ucinet for windows: Software for social network analysis. Harvard, MA: Analytic Technologies.

Borgatti, S. P., Mehra, A., Brass, D. J., \& Labianca, G. (2009). Network analysis in the social sciences. Science, 323(5916), 892-895. https://doi.org/10.1126/science.1165821

Buela-Casal, G. (2003). Evaluación de la calidad de los artículos y de las revistas científicas: Propuesta del factor de impacto ponderado y de un índice de calidad. Psicothema, 15(1), 23-35. https://doi.org/10.1016/j.acalib.2011.02.006

Casquero, O., Ovelar, R., Romo, J., \& Benito, M. (2015). Reviewing the differences in size, composition and structure between the personal networks of high- and low-performing students. British Journal of Educational Technology, 46(1), 16-31. https://doi.org/10.1111/bjet.12110

Chiu, C. M., Hsu, M. H., \& Wang, E. T. G. (2006). Understanding knowledge sharing in virtual communities: An integration of social capital and social cognitive theories. Decision Support Systems, 42(3), 1872-1888. https://doi.org/10.1016/j.dss.2006.04.001

Dholakia, U. M., Bagozzi, R. P., \& Pearo, L. K. (2004). A social influence model of consumer participation in network -and small-group-based virtual communities. International Journal of Research in Marketing, 21(2), 241-263. http://doi.org/10.1016/j.ijresmar.2003.12.004

Diestro, A., Ruiz-Corbella, M., \& Galán, A. (2017). Calidad editorial y científica en las revistas de educación. Tendencias y oportunidades en el contexto 2.0. Revista de Investigación Educativa, 35(1), 235-250. https://doi.org/10.6018/rie.35.1.244761

Doreian, P., \& Fararo, T. J. (1985). Structural equivalence in a journal network. Journal of the American Society for Information Science, 36(1), 28-37. https://doi.org/10.1002/asi.4630360103

Eagly, R. (1975). Economics journals as a communications network. Journal of Economic Literature, 13(3), 878-888.

Franco, A., Sanz, J., \& Culebras, J. M. (2016). Publicar en castellano, o en cualquier otro idioma que no sea inglés, negativo para el factor de impacto y citaciones. Journal of Negative and No Positive Results, 1(2), 65-70. https://doi.org/10.19230/jonnpr.2016.1.2.1005

Gantman, E. R., \& Dabós, M. P. (2018). Research output and impact of the fields of management, economics, and sociology in spain and france: An analysis using google scholar and scopus. Journal of the Association for Information Science and Technology, 69(8), 1054-1066. https:// doi.org/10.1002/asi.24020

Gargouri, Y., Hajjem, C., Lariviére, V., Gingras, Y., Carr, L., Brody, T., \& Harnad, S. (2010). Selfselected or mandated, open access increases citation impact for higher quality research. PLoS. ONE, 5(10). Retrieved from http://doi.org/10.1371/journal.pone.0013636

Harnad, S., \& Brody, T. $(2004,6)$. Comparing the Impact of Open Access vs Non OA Articles in the Same Journals. D-Lib. Magazine, 10(6). Retrieved from http://doi.org/10.1045/june2004 -harnad

Harzing, A. W. (2007). Publish or Perish. Retrieved from https://harzing.com/resources/publish-or -perish

Haythornthwaite, C. (1996). Social network analysis: An approach and technique for the study of 
Information Exchange. Information Exchange. Library \& Information Science Research, 18(4), 323-342. https://doi.org/10.1016/S0740-8188(96)90003-1

Kondakci, Y., Bedenlier, S., \& Zawacki-Richter, O. (2018). Social network analysis of international student mobility: uncovering the rise of regional hubs. Higher Education, 75(3), 517-535. https://doi.org/10.1007/s10734-017-0154-9

Leon-Sarmiento, F. E., Leon-S, M. E., \& Contreras, V. A. (2007). El impacto de factor de impacto: ¿mito o realidad? Colombia Médica, 38(3), 290-296. Retrieved from http://132.248.9.34/ hevila/Colombiamedica/2007/vol38/no3/13.pdf

Liu, Z., \& Wang, C. (2005). Mapping interdisciplinarity in demography: a journal network analysis. Journal of Information Science, 31(4), 308-316. https://doi.org/10.1177/0165551505054176

López-Navarro, I., Moreno, A. I., Quintanilla, M. A., \& Rey-Rocha, J. (2015). Why do I publish research articles in english instead of my own language? Differences in spanish researchers' motivations across scientific domains. Scientometrics, 103(3), 939-976. https://doi.org/10 .1007/s11192-015-1570-1

Marín, V. I., Duart, J. M., Galvis, A. H., \& Zawacki-Richter, O. (2018). Thematic analysis of the international journal of educational Technology in Higher Education (ETHE) between 2004 and 2017. International Journal of Educational Technology in Higher Education, 15(1), 101186. https://doi.org/10.1186/s41239-018-0089-y

Marín, V. I., Zawacki-Richter, O., Pérez, A., \& Salinas, J. (2017). Educational Technology Trends in the Ibero-american World: 20 Years of the Edutec-E Journal. Edutec-e. Revista Electrónica de Tecnología Educativa, 59. https://doi.org/edutec.2017.59.836

Otte, E., \& Rousseau, R. (2002). Social network analysis: a powerful strategy, also for the information sciences. Journal of Information Science, 28(6). https://doi.org/10.1177/016555150202800601

Rafel, N. (2016). Atrapados en el sistema. Revista d'Arqueologia de Ponent.

Rice, R. E., Borgman, C. L., Bednarski, D., \& Hart, P. J. (1989). Journal-to-journal citation data: Issues of validity and reliability. Scientometrics, 15(3-4), 257-282. https://doi.org/10.1007/ BF02017202

Robinson-García, N., Repiso, R., \& Torres-Salinas, D. (2018). Perspectiva y retos de los profesionales de la evaluación científica y la bibliometría. El Profesional de La Información, 27(3), 461-466. https://doi.org/10.3145/epi.2018.may.01

Ruiz-Corbella, M., Galán, A., \& Diestro, A. (2014). Scientific journals on education in Spain: Evolution and prospects for the future. RELIEVE - Revista Electrónica de Investigación y Evaluación Educativa, 20(2). https://doi.org/10.7203/relieve.20.2.4361

Salager-Meyer, F. (2015). Peripheral scholarly journals: from locality to globality. Ibérica, 30, 15-36. Retrieved from http://www.redalyc.org/articulo.oa?id=287042542002

Tibaná-Herrera, G., Fernández-Bajón, M. T., \& Moya-Anegón, F. (2018). Categorization of an emerging discipline in the world publication system (SCOPUS): E-learning. International Journal of Educational Technology in Higher Education, 15(21), 10-1186. https://doi.org/10 .1186/s41239-018-0103-4

Torres-Salinas, D., Bordons, M., Giménez-Toledo, E., López-Cózar, E. D., Jiménez-Contreras, E., \& Sanz-Casado, E. (2010). Clasificación integrada de revistas científicas (CIRC): propuesta de categorización de las revistas en ciencias sociales y humanas. El Profesional de La Información, 19(6), 675-684. https://doi.org/10.3145/epi.2010.nov.15

Torres-Salinas, D., Cabezas-Clavijo, A., \& Jiménez-Contreras, E. (2013). Altmetrics: New indicators for scientific communication in web 2.0. Comunicar, 41, 53-60. https://doi.org/10.3916/ C41-2013-05

Torres-Salinas, D., Castillo-Valdivieso, P. A., Pérez-Luque, A., \& Romero-Frías, E. (2018). Altmétricas a nivel institucional: visibilidad en la Web de la producción científica de las univer- 
sidades españolas a partir de Altmetric.com. El Profesional de la Información, 27(3), 483-492. https://doi.org/10.3145/epi.2018.may.03

Torres-Salinas, D., \& Repiso, R. (2016). Clasificación CIRC. Anuario ThinkEPI, 10, 237-239. http:// doi.org/10.3145/thinkepi.2016.47

Urbano, C., Somoza-Fernández, M., Rodríguez-Gairín, J. M., Ardanuy, J., Guardiola, E., Pons, A., \& Cosculluela, A. (2005). MIAR: una base de datos para la identificación y la evaluación de la difusión secundaria de revistas de humanidades y ciencias sociales. Jornadas Españolas de Indicadores Para La Evaluación de La Ciencia y La Tecnología. Madrid: Consejo Superior de Investigaciones Cientificas (España). Retrieved from http://eprints.rclis.org/6267/

Vargas, J. L., Piedra, N., Chicaiza, J., Tovar, E., Blázques, M., Castro, M., \& Landaluce, A. (2010). Meta-analysis of the TAEE project applying social network analysis. In S. de publicaciones EUI UPM (Ed.), IEEE EDUCON 2010 Conference (pp. 129-136). Madrid: IEEE. https:// doi.org/10.1109/EDUCON.2010.5493061

Wasserman, S., \& Faust, K. (1994). Social network analysis: Methods and applications. Cambridge; New York: Cambridge University Press. https://doi.org/10.1017/CBO9780511815478

Xhignesse, L. V., \& Osgood, C. E. (1967). Bibliographical citation characteristics of the psychological journal network. American Psychologist, 22, 770-791. https://doi.org/10.1037/h0024961

Zawacki-Richter, O., Alturki, U., \& Aldraiweesh, A. (2017). Review and content analysis of the International Review of Research in Open and Distance/Distributed Learning (2000-2015). International Review of Research in Open and Distance Learning, 18(2), 1-26. https://doi.org/ 10.19173/irrodl.v18i2.2806

Zawacki-Richter, O., \& Anderson, T. (2011). The geography of distance education - bibliographic characteristics of a journal network. Distance Education, 32(3), 441-456. Retrieved from http://www.ijede.ca/index.php/jde/article/view/661

Zawacki-Richter, O., Anderson, T., \& Tuncay, N. (2010). The growing impact of open access distance education journals: A bibliometric analysis. International Journal of E-Learning \& Distance Education, 24(3). Retrieved from http://www.ijede.ca/index.php/jde/article/view/661

Zawacki-Richter, O., \& Latchem, C. (2018). Exploring four decades of research in Computers \& Education. Computers and Education, 122(April), 136-152. https://doi.org/10.1016/ j.compedu.2018.04.001

Zawacki-Richter, O., \& Naidu, S. (2016). Mapping research trends from 35 years of publications in. Distance Education. Distance Education, 37(3), 245-269. https://doi.org/10.1080/01587919 .2016 .1185079

Zhang, Y., Lun, H., \& Yang, Z. (2017). Is Google Scholar useful for the evaluation of non english scientific journals? The case of chinese journals. iConference 2017 Proceedings (pp. 241-261). Illinois, US: iSchools. Retrieved from http://doi.org/10.9776/17025 